AGH DRILLING, OIL, GAS • Vol. 30 • No. $1 \cdot 2013$

http://dx.doi.org/10.7494/drill.2013.30.1.231

\author{
Moussa Thiam*, Dariusz Knez*
}

\title{
BEHAVIOR OF HYDRAULIC FRACTURE PROPAGATION IN NATURALLY FRACTURED RESERVOIR**
}

\section{INTRODUCTION}

Geologically, the natural fracture is a discontinuity or local separation in the plane, which devise the rock in two or many parts. When, the stress on the rock is greater than the rock resistance, this leads to the loss of cohesion under the part with weak resistance. The fractures, which can provided the permeability of fluid movement as water, oil and gas are often characterized by the profound fissures or small cracks. So with these characteristics, the good reservoirs of hydrocarbon or aquifers can be the highly fractured rock.

The fractures are caused as the result of compression, traction or shear stress. There are three main types of fractures which occurs regardless the mechanism. These types are:

- Mode I: fissure - opening mode, the tensile stress is perpendicular to the fissure plane;

- Mode II: fissure - sliding mode, shear stress acting parallel to the fissure plane and perpendicular to the fissure front;

- Mode III: fissure - tearing mode, shear stress acting parallel to the fissure plane and parallel to the fissure front.

Fractures with low porosity, can store a large quantity of hydrocarbons that can be recovered at very high rates. They play a very important role in the petroleum production. However, natural fractures can act as potential dangers when they have a very high permeability, which can caused control problems of wells and cause especially the difference in pressure equilibrium during drilling. So to prevent the problems coming from natural fractures (Eruption, loss of hydrostatic pressure) and make the most of their benefits, we have to take care of natural fractures by studying seriously influence the most of all parameters.

* AGH University of Science and Technology

** Research number 11.11.190.55 


\section{FRACTURE INTERACTION}

For understanding well the effect of hydraulic fracture propagation in the naturally fractured reservoir was chosen three various models which have provided analytic equations. Numerical solution was applied for predicting the behavior of natural fracture when it interacts with hydraulic fracture. Blanton, Warpinski and Tuefel derived fracture interaction criteria relating differential stress and angle of approach. Renshaw provided a criterion for crossing across unbounded interfaces. Figure 1 shows graphical presentation of the hydraulic fracture of height $\mathrm{l}$, length $\mathrm{H}$ and width $\mathrm{w}$ under the pressure of the hydraulic fracturing fluid.

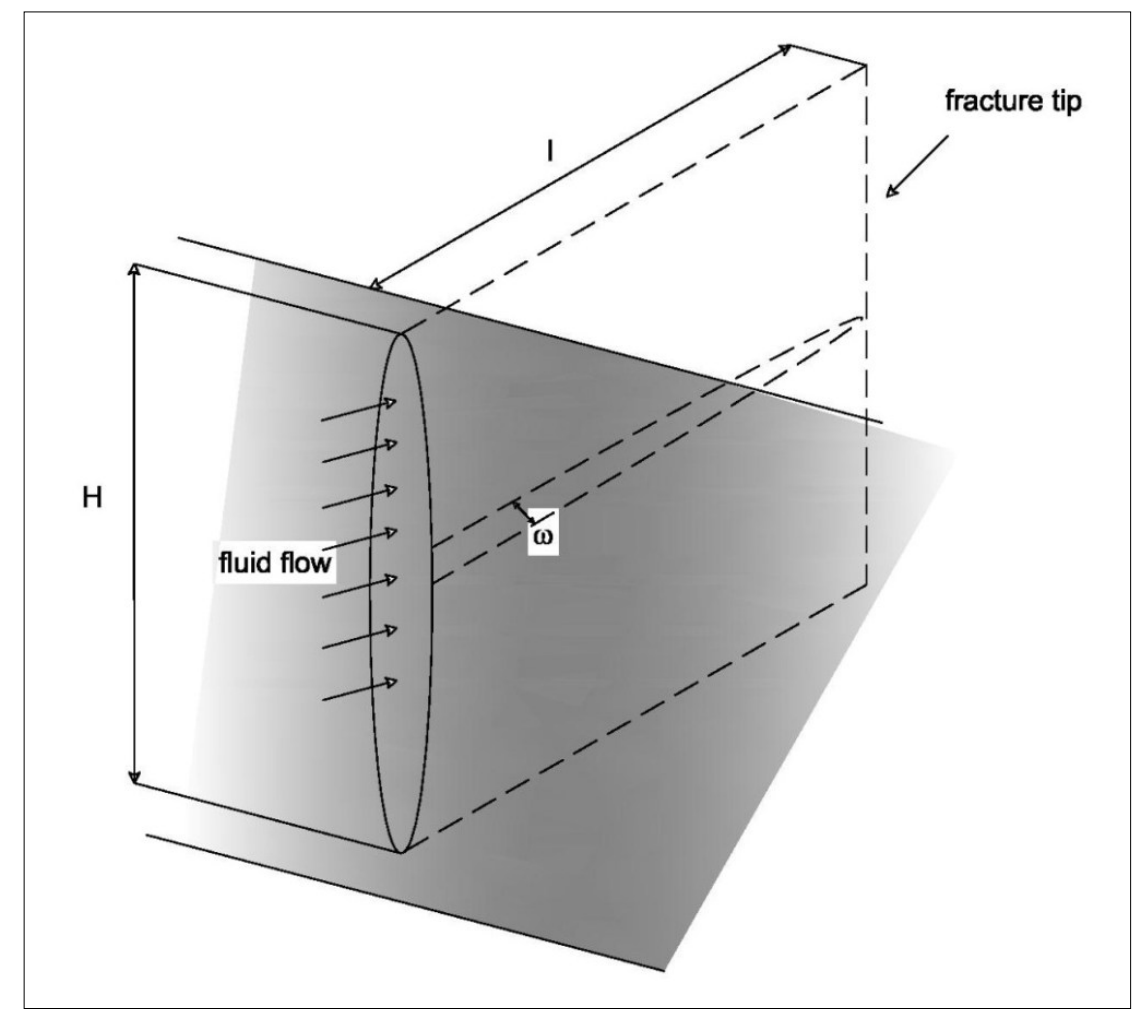

Fig. 1. Schematic illustration of hydraulic fracturle model.

The parameters $l, H$ and $w$ are fracture half length, height and width respectively

During hydraulic fracturing process in naturally fractured reservoir some part of fractures will propagate using natural fracture path. Figure 2 shows schematic view of intersection between natural fracture and hydraulic fracture.

At the intersection point one of the most important factor is the angle of intersection which is the most sensitive parameter for Blanton, Warpinski and Teufel criterion. But for the specific case, when the intersection angle is $90^{\circ} \mathrm{C}$, Renshaw criterion can be applied. 
So when the natural and hydraulic fractures are orthogonal, then the three criterions are available.

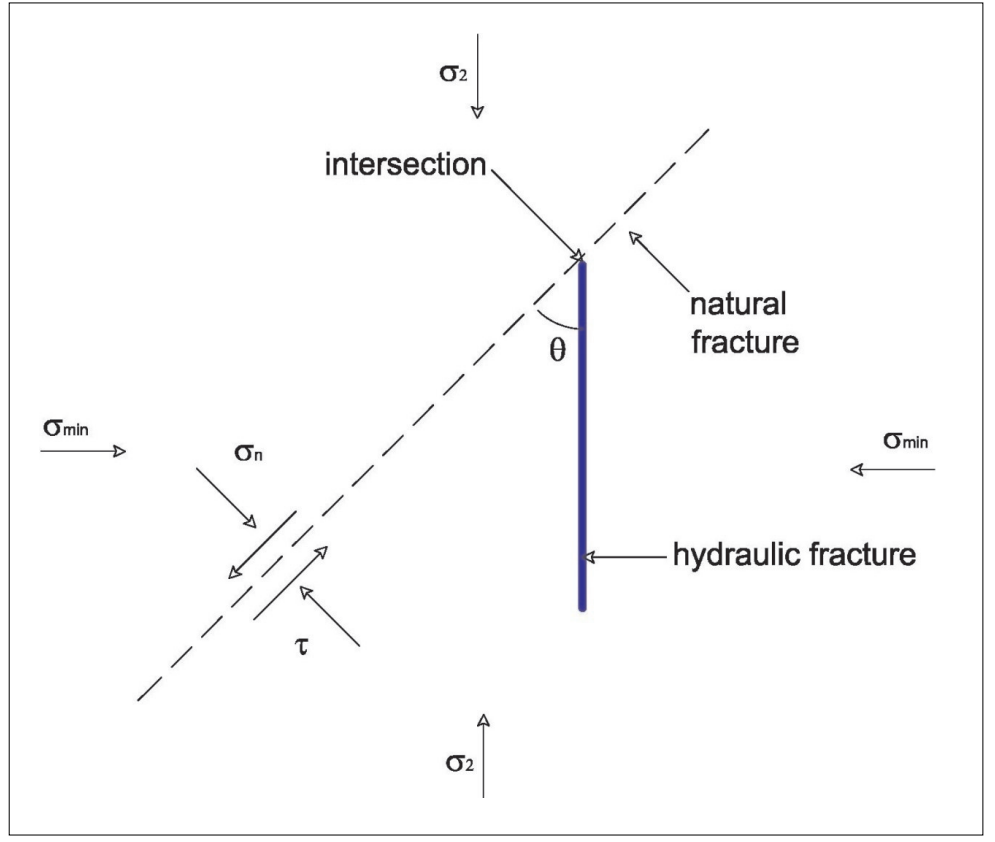

Fig. 2. Schematic plan view of the hydraulic fracture approaching and intersecting a natural fracture

\section{MODELS DESCRIPTION}

Blanton had announced two criterions for opening and crossing based on the results of laboratory experiences, according to him, the criterion can be stated as follows:

- If the pressure at the intersection is greater than the normal stress acting on the natural fracture, then opening will occur;

- If the pressure required for re-initiation is less than the opening pressure, then crossing will occur.

The mathematical form of this criterion can be written as:

- For opening:

$$
\sigma_{t}+T \leq P
$$

- For crossing:

$$
\sigma_{n}<P
$$


where:

$P$ - the pressure in the fracture,

$T$ - magnitude of tensile stress require to fracture rock,

$\sigma_{n}-$ normal stress acting on the plane of the natural fracture,

$\sigma_{t}-$ is the normal stress component acting parallel to the natural fracture, it depends not only on far-field stresses and pressure in the fracture but also the geometry of the interaction zone as well as frictional slippage and opening along the natural fracture.

After many transformations, the final crossing expression is given by Blanton as:

$$
\frac{\sigma_{1}-\sigma_{2}}{2}>\frac{-1}{\cos 2 \theta-b \sin 2 \theta}
$$

$b, V\left(x_{0}\right)$ and $x_{0}$ are described by:

$$
\begin{aligned}
& b=\frac{1}{2}\left[\mathrm{v}\left(x_{0}\right)-\frac{x_{0}-l}{K_{f}}\right] \\
& v\left(x_{0}\right)=\frac{1}{\pi}\left[\left(x_{0}+l\right) \cdot \ln \left(\frac{x_{0}+l+a}{x_{0}+a}\right)+\left(x_{o}-l\right) \cdot \ln \left(\frac{x_{0}-l-a}{x_{0}-a}\right)+C \cdot \ln \left(\frac{x_{0}+l+a}{x_{0}-l-a}\right)\right] \\
& x_{0}=\frac{(1+a)+\exp o\left(\pi / 2 K_{f}\right)}{1+\exp o\left(\pi / 2 K_{f}\right)}
\end{aligned}
$$

where:

$\sigma_{1}, \sigma_{3}-$ maximum and minimum principal stress acting on the plane of the natural fracture,

$a$ - length of the zone of slippage, the region from $-l$ to $+l$ is the open section of the natural fracture,

$\theta$ - angle of interaction,

$K_{f}-$ coefficient of friction,

$X_{0}$ - point of reinitiating of hydraulic fracture,

$C$ - zone of shear slippage in the natural fracture, Beyond the open section to points $\pm(1+a)$ is the region where the shear stress is increasing until it is equal to the farfield shear stress.

The interaction angle was found to be the most sensitive parameter in determining the fracture propagation, this criterion agree very well with the experimental results.

The second was choosed Warpinski and Teufel model. For this criterion, the shear slippage occurs on the natural fracture plane when: 


$$
|\tau|>\tau_{0}+K_{f}\left(\sigma_{n}-P\right)
$$

Using the linear frictional law, equation 7 can be shown in the form:

$$
|\tau|=\tau_{0}+K_{f}\left(\sigma_{n}-P\right)
$$

where:

$$
K_{f}-\text { coefficient of friction, }
$$

$\sigma_{n}-P$ - effective normal stress acting on the natural fracture plane,

$\tau_{0}-$ inherent shear strength of the natural fracture plane.

From the 2D stress resolution, the shear stress and normal stress acting on the natural fracture plane are:

$$
\tau=\frac{\left(\sigma_{1}-\sigma_{3}\right) \sin 2(90-\theta)}{2}
$$

and

$$
\tau=\frac{\left(\sigma_{1}-\sigma_{3}\right)}{2}+\frac{\left(\sigma_{1}-\sigma_{3}\right) \cos 2(90-\theta)}{2}
$$

The pressure at the intersection point between hydraulic fracture and natural fracture is given as:

$$
P=\sigma_{3}+P_{\sigma}
$$

$P_{\sigma}$ is the treatment overpressure.

Substituting, eq. (9) and eq. (10) in eq. (7), the shear slippage criterion became:

$$
\left(\sigma_{1}-\sigma_{3}\right)>\frac{\left(2 \tau_{0}-2 P_{\sigma} K_{f}\right)}{\left(\sin 2 \theta+K_{f} \cos 2 \theta-K_{f}\right)}
$$

After transforming equation (12), the new mathematical form for shear slippage used in new computer program developed in The Drilling and Geoengineering Department. It does comparison between the treatment overpressure and the function given at the right of inequality:

$$
P_{\sigma}>\frac{\tau_{0}}{K_{f}}-\frac{\left(\sigma_{1}-\sigma_{3}\right)}{2 K_{f}} \cdot\left(\sin 2 \theta+K_{f} \cos 2 \theta-K_{f}\right)
$$

The condition for natural fracture dilatation is

$$
P=\sigma_{n}
$$

Using eq. (10) and eq. (11), the new form for expression (14) can be written as:

$$
P_{\sigma}>\frac{\left(\sigma_{1}-\sigma_{3}\right)(1-\cos 2 \theta)}{2}
$$


Renshaw announced a simple criterion for crossing, available for orthogonal interactions, can be written mathematically as:

$$
\frac{-\sigma_{3}}{T_{0}-\sigma_{1}}>\frac{0.35+\frac{0.35}{K_{f}}}{1.06}
$$

\section{ANALYSES OF MODELS}

Renshaw's criterion is available for orthogonal fractures. From expression 16 can be found interaction criteria. For each rock $K_{f}$ is known, so right side term is constant. This condition is depending on the parameters $T_{0}, \sigma_{1}, \sigma_{3}$, and $K_{f}$. Using new computer program all parameters necessary for this criterion were calculated automatically and this way can be easy found answer if natural fracture interacts with hydraulic fracture or not. For some cases of shallow layers criterion can be not valid because $T_{0}-\sigma_{1}$ must be different to zero. Blanton's criterion is announced for opening or crossing, mathematical description assumes opening when the opening pressure is greater than pressure required for re-initiation. Condition depends on principal insitu stresses $\sigma_{1}, \sigma_{3}$ and the angle of interaction, $\theta$. Crossing occurs when the expression (3) is satisfied depending on the parameters $\sigma_{1}, \sigma_{3}, \theta$, $K_{f}, C, l, X_{0}, b, V$. Thes constraints for the function are, that these terms $x_{0}-1-\mathrm{a} ; x_{0}-1$ must be different to zero. Computer program permits choice of intersection parameters an calculates result.

Warpinski and Tuefel's criterion is based on analyze of experimental results. It is available for shear slippage and dilatation of the natural fracture when it intersects the hydraulic fracture. Shear slippage occurs when the expression (13) is true with all constraints depending on the parameters: $T_{0}, P_{\sigma}, \sigma_{1}, \sigma_{3}, \theta, K_{f}$. Natural fracture dilate in case when the condition (15) is satisfied. The computer program gives automatically the result for each condition. The most sensitive parameter is the angle of intersection between natural fracture and hydraulic fracture. It was found that these three models give approximately the same result for crossing when we use the same parameters. So using these program, it can be a mean for Engineer or Operator to have some idea about the behavior of the hydraulic fracture in the natural fracture reservoir to predict solutions in order to achieve the objectives of the operation. Some examples are developed in the tables 1 to 3 . Table 1 shows data and results for case where just the angle of interaction is constant but all other parameters are changeable to take in consideration Renshow's criterion (which is available only when the hydraulic and natural fractures are orthogonal). When the angle become changeable, as in the Table 2, then we can see the impact of interaction angle in the behavior of hydraulic fracture in the natural fracture reservoir for Blaton and Warpinski and Tuefel methods but Renshaw's criterion is not available. First line in this table was used to search for influence of remaining parameters. Results from new computer program are shown in the Table 3. For calculations was assumed $K_{f}=0.5 ; T_{0}=8 \mathrm{~Pa} ; r=\rho=2500 \mathrm{~kg} / \mathrm{m}^{3} ; P=9810000 \mathrm{~Pa}$. 

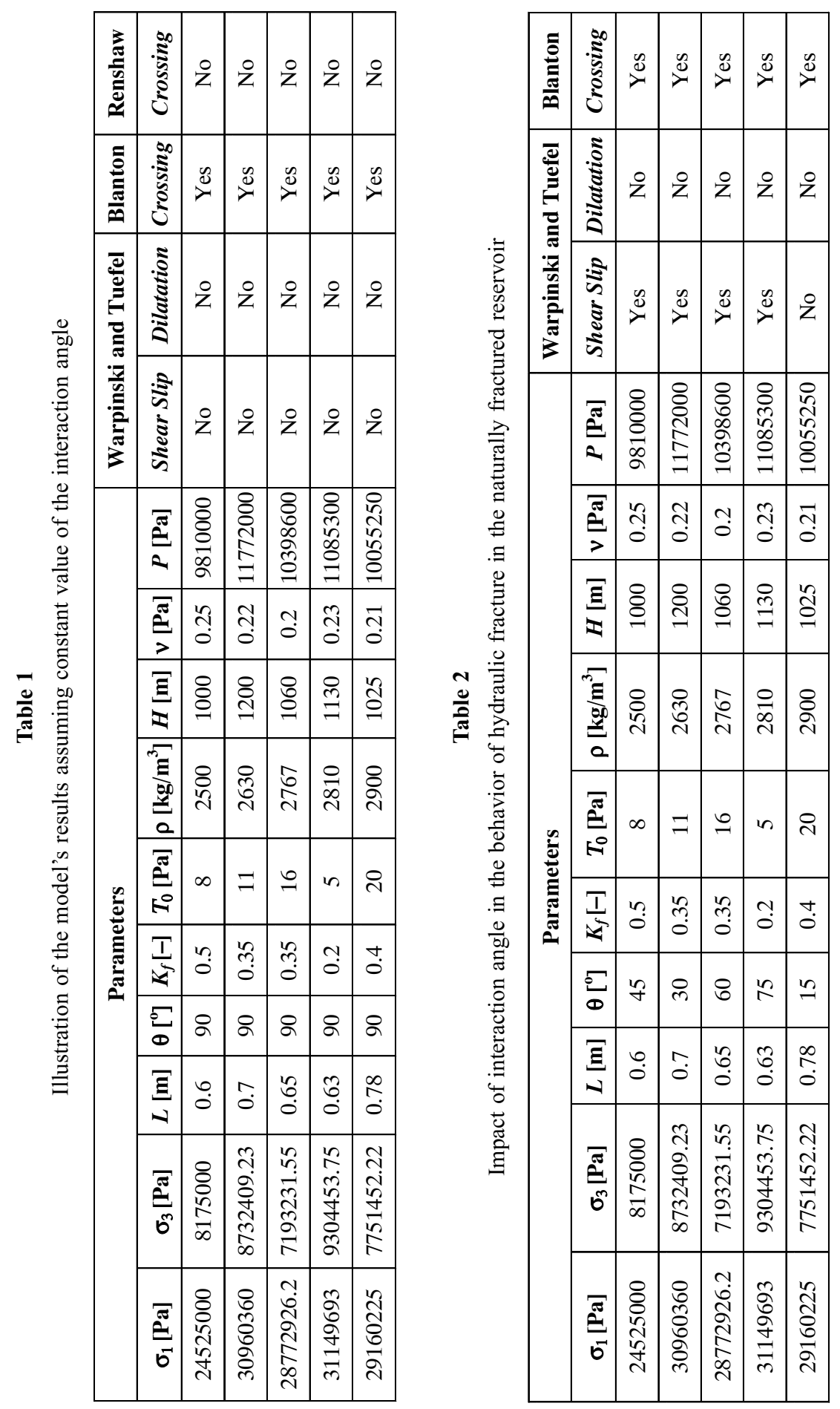
Table 3

Computational results as function of $\theta$, when the other parameters are constant

\begin{tabular}{|c|c|c|c|c|c|}
\hline \multicolumn{3}{|c|}{ Parameters } & \multicolumn{2}{|c|}{ Warpinski and Tuefel } & \multirow{2}{*}{$\begin{array}{l}\text { Blanton } \\
\text { Crossing }\end{array}$} \\
\hline$\sigma_{1}[\mathbf{P a}]$ & $\sigma_{3}[\mathbf{P a}]$ & $\theta\left[{ }^{0}\right]$ & Shear Slip & Dilatation & \\
\hline 24525000 & 8175000 & 5 & No & Yes & Yes \\
\hline 24525000 & 8175000 & 10 & No & Yes & Yes \\
\hline 24525000 & 8175000 & 20 & No & Yes & Yes \\
\hline 24525000 & 8175000 & 30 & No & Yes & Yes \\
\hline 24525000 & 8175000 & 32 & No & Yes & Yes \\
\hline 24525000 & 8175000 & 32.09 & No & Yes & Yes \\
\hline 24525000 & 8175000 & 32.1 & Yes & Yes & Yes \\
\hline 24525000 & 8175000 & 40 & Yes & Yes & Yes \\
\hline 24525000 & 8175000 & 50 & Yes & Yes & Yes \\
\hline 24525000 & 8175000 & 55 & Yes & Yes & Yes \\
\hline 24525000 & 8175000 & 57 & Yes & Yes & Yes \\
\hline 24525000 & 8175000 & 57.8 & Yes & Yes & Yes \\
\hline 24525000 & 8175000 & 57.9 & Yes & Yes & Yes \\
\hline 24525000 & 8175000 & 57.95 & Yes & Yes & Yes \\
\hline 24525000 & 8175000 & 57.96 & Yes & No & Yes \\
\hline 24525000 & 8175000 & 57.97 & Yes & No & Yes \\
\hline 24525000 & 8175000 & 58 & Yes & No & Yes \\
\hline 24525000 & 8175000 & 60 & Yes & No & Yes \\
\hline 24525000 & 8175000 & 70 & Yes & No & Yes \\
\hline 24525000 & 8175000 & 80 & Yes & No & Yes \\
\hline 24525000 & 8175000 & 90 & Yes & No & Yes \\
\hline
\end{tabular}

\section{CONCLUSIONS}

1. This paper presents studies on the influence of natural fractures on the hydraulic fracture propagation using three criterions which are: Blanton's criterion, Warpinski and Teufel's Criterion, and Renshaw's criterion. The effect of natural fracture for the propagating way can be crossing or opening (dilatation). 
2. There are areas where models give the same results, but there are also conditions with different answers from each model. So farther experiments are necessary to define precisly scope of application.

3. New computer program allows easy use of the mathematical forms of these conditions for crossing or opening depending on many parameters. Engineers can use it to predict the behavior of the hydraulic fracture depending on the natural fracture.

4. The program can be useful additive for engineers making standard or simulation aided projects in hydraulic fracturing and geotechnical field.

\section{Nomenclature}

$a$ - length of the slippage zone, $\mathrm{m}$

$b$ - factor for Blanton's crossing criterion, dimensionless

$K_{f}$ - frictional coefficient, dimensionless

$l$ - length of the natural fracture, $\mathrm{m}$

$P$ - pressure at the intersection, $\mathrm{Pa}$

$P_{\sigma}-$ treatment over pressure, $\mathrm{Pa}$

$T_{0}-$ Rock Tensile strength, $\mathrm{Pa}$

$X_{0}-$ point of reinitiating of hydraulic fracture, $\mathrm{m}$

$\theta-$ angle of interaction, ${ }^{o}$

$\mu$ - fluid viscosity, $\mathrm{Pa} \cdot \mathrm{s}$

$v$ - Poisson ratio, dimensionless

$\sigma_{1}-$ maximum principal stress, $\mathrm{Pa}$

$\sigma_{3}-$ minimum principal stress, $\mathrm{Pa}$

$\sigma_{t}-$ stress acting parallel to the natural fracture plane, $\mathrm{Pa}$

$\sigma_{n}-$ stress acting perpendicular to the natural fracture plane, $\mathrm{Pa}$

$\tau_{0}-$ inherent shear strength of the material, $\mathrm{Pa}$

$\tau$ - shear stress acting on the plane of the natural fracture, $\mathrm{Pa}$

\section{REFERENCES}

[1] Blanton T.L.: An Experimental Study of Interaction Between Hydraulically Induced and Pre-Existing Fractures. SPE 10847, presented at the SPE/DOE unconventional Gas Recovery Symposium, Pittsburg, Pennsylvania, 16-18 May 1982.

[2] Blanton T.L.: Propagation of Hydraulically and Dynamically Induced Fractures in Naturally Fractured Reservoirs. SPE 15261, presented at the SPE Unconventional Gas Technology Symposium, Louisville, KY, 18-21 May 1986.

[3] Warpinski N.R., Teufel L.W.: Influence of Geologic Discontinuities on Hydraulic Fracture Propagation. JPT 209-220, February 1987. 
[4] Warpinski N.R.: Hydraulic Fracturing in Tight, Fissured Media. JPT 146-152, 208209, February 1991.

[5] Renshaw C.E., Pollard D.D.: An Experimentally Verified Criterion for Propagation across Unbounded Frictional Interfaces in Brittle, Linear Elastic Materials. International Journal of Rock Mechanics Mining Science and Geomechanics, 32, 3, 1995 , 237-249.

[6] Jaeger J.C., Cook N.G.W.: Fundamentals of Rock Mechanics. Halsted Press, New York, 1976. 